\title{
Percutaneous nephrolithotomy under spinal anesthesia is safe and effective
}

\begin{abstract}
Purpose: To present our results for percutaneous nephrolithotripsy (PCNL) performed under spinal anesthesia (SA).

Materials and methods: Between November 2012 and August 2016, 172 patients underwent PCNL under SA. Demographic data, stone and urinary system characteristics, operation parameters, and postoperative findings have been recorded for all patients.

Results: The mean age of 172 patients, 59 male and 113 female, was $48.4 \pm 17.0$ years. Mean stone load was $640 \pm 420 \mathrm{~mm}^{2}$, mean operation time was $61.5 \pm 15.5 \mathrm{~min}$, and mean duration of hospitalization was $42 \pm 18$ hours. Total success rate was $94 \%$. Seven patients (4.1\%) had postoperative fever, 10 patients $(5.8 \%)$ had headache, and 5 patients $(2.9 \%)$ had hemorrhage. Prolonged drainage from the nephrostomy tract and perirenal hematoma were seen in $3(1.7 \%)$ and $2(1.1 \%)$ patients, respectively.
\end{abstract}

Conclusion: In a group of well-selected patients, PCNL can be performed efficiently and safely under SA with good success rate and low complication rate.

Keywords: percutaneous nephrolithotripsy, spinal anesthesia, complication, stone-free rate
Volume 4 Issue 3 - 2017

\author{
Ersan Bulut' ${ }^{\prime}$ Murat Akand, ${ }^{2}$ Mehmet \\ Solakhan ${ }^{3}$ \\ 'Department of Urology, Gaziantep State Hospital,Turkey \\ ${ }^{2}$ Department of Urology, Selcuk University, School of Medicine, \\ Turkey \\ ${ }^{3}$ Department of Urology, Gaziantep Medical Park Hospital, \\ Turkey
}

Correspondence: Murat Akand, Selçuk Üniversitesi, Alaeddin Keykubat Kampüsü,Tıp Fakültesi Hastanesi, E-Blok, Kat: I, Üroloji Polikliniği, 42075 Selçuklu/Konya/Türkiye,Tel +90 532 74383 33, Fax +90332 241 21 84,

Email drmuratakand@yahoo.com

Received: February 25, 2017 | Published: March 27, 2017
Abbreviations: PCNL, percutaneous nephrolithotripsy; SA, spinal anesthesia; GA, general anesthesia; ESWL, extra corporeal shock wave lithotripsy; PCS, pelvicalyceal system; S, Stones;

KUB, kidney-ureter-bladder; DJ, double-J; CIRF, clinically insignificant residual fragment; US, ultrasound; CT, computed tomography

\section{Introduction}

Urinary stone disease is a common health problem and has an incidence of $4-20 \%$ worldwide. ${ }^{1}$ Percutaneous nephrolithotripsy (PCNL), an efficient and reliable modality in the surgical management of stone disease, has been first described by Fernström and Johansson in $1976 .^{2}$ The popularity of this minimally invasive technique has risen gradually during the last 30 years due to its advantages such as short hospitalization time, low morbidity rates, high success rates and low costs. ${ }^{3}$ PCNL is offered as the first choice of treatment not only for stones bigger than $2 \mathrm{~cm}$, but also stones resistant or not appropriate for extra corporeal shock wave lithotripsy (ESWL). ${ }^{4}$ Although this operation is generally performed under general anesthesia (GA), spinal anesthesia (SA) can also be used for appropriate patients on the discretion of the surgeon, anesthetist, and the patient. There are some studies that report PCNL performed under SA is as successful and safe as the ones performed with GA..$^{5-10}$ Herein, we report our experience for 172 PCNL cases under SA performed by a single surgeon.

\section{Materials and methods}

The study was performed in accordance with the ethical standards laid down in the 1964 Declaration of Helsinki and its later amendments, with a waiver of informed consent because of its retrospective fashion. The confidentiality of patient data was guaranteed. A computerized database of consecutive 172 patients treated with PCNL under SA between November 2012 and August 2016 was retrospectively analyzed. Demographic data, stone and urinary system characteristics (stone size, localization and laterality, kidney abnormality, previous history of surgery and/ or ESWL), operation parameters (operation duration, fluoroscopy time, tract number and location, blood transfusion, complications), and postoperative findings (hospitalization time, blood transfusion, complications, stone-free rate) have been recorded for all patients.

\section{Spinal anesthesia technique}

After receiving I.V. 3-5 mg midazolam for sedation and an I.V. infusion of $15 \mathrm{~mL} / \mathrm{kg}$ saline in $15 \mathrm{~min}$, all patients were positioned laterally onto the operation side and a mixture of $15-20 \mathrm{mg}$ of $0.5 \%$ bupivacaine hydrochloride and $25 \mathrm{mcg}$ fentanyl was given via a spinal needle into the subarachnoid space through L3-L4 intervertebral space.

\section{PCNL technique}

After SA performed, an open-ended $6 \mathrm{Fr}$ catheter was placed into ipsilateral ureter in lithotomy position, and then fixed to a 16 Fr urethral catheter. Following positioning of the patient in prone position and required draping, pelvicalyceal system (PCS) was visualized with radio-opaque agent under fluoroscopy. The most appropriate posterior calyx was determined and puncture to PCS was performed with an $18 \mathrm{G}$ TLA needle, followed by introduction of a 0.038-inch guide wire to the collecting system, and tract dilatation with Amplatz renal dilatator up to $30 \mathrm{Fr}$. Stone(s) were fragmented with pneumatic lithotripter and taken out with graspers. Stone-free status was confirmed with either direct vision with nephroscope or fluoroscopy. In patients with stones in different calyxes, an additional 
access was made if the existing one was not enough for achieving maximal stone-free status. A $14 \mathrm{Fr}$ nephrostomy tube was placed through the renal sheath after the completion of the procedure. The time beginning from the insertion of the TLA needle into collecting system to the insertion of the nephrostomy tube was determined as the operation time. A complete blood count and kidney-ureter-bladder (KUB) X-ray were performed, and urethral catheter was taken out on the first postoperative day. Stone fragments equal or smaller than $4 \mathrm{~mm}$ were considered as clinically insignificant residual fragment (CIRF). All patients were called for a follow-up 1 week after the surgery for determining the stone-free status either with KUB x-ray or with urinary ultrasound (US) or computed tomography (CT) for nonopaque stones. Postoperative complications were graded according to modified Clavien-Dindo classification.

\section{Results}

Of 172 patients, $113(65.7 \%)$ were female and 59 (34.3\%) were male. Mean age was $48.4 \pm 17.0$ years, and mean stone load was $640 \pm 420 \mathrm{~mm}^{2}$. Mean operation time was $61.5 \pm 15.5 \mathrm{~min}$, in which 21 patients $(12.2 \%)$ had intercostal access and 151 patients $(87.8 \%)$ had subcostal access. Mean duration of hospitalization was $42 \pm 18$ hours. Demographic and operation characteristics are listed in Table 1. Complete stone-free rate was $89 \%$, and $5 \%$ of the patients had a CIRF $(\leq 4 \mathrm{~mm})$; thus giving a rate of $94 \%$ for total success rate.

Table I Demographic data of the patients and operation parameters

\begin{tabular}{|l|l|}
\hline Parameter & $n=172$ \\
\hline Sex(M/F) & $59 / 113$ \\
\hline Mean Age (years) & $48.4 \pm 17.0$ \\
\hline Mean Stone Burden (mm²) & $640 \pm 420$ \\
\hline Mean Operation Duration (min) & $61.5 \pm 15.5$ \\
\hline Mean Fluoroscopy Time (min) & $4.1 \pm 2.7$ \\
\hline Mean Hospitalization Duration (hours) & $42 \pm 18$ \\
\hline Intercostal Access (n,\%) & 21 (I2.2\%) \\
\hline Subcostal Access (n,\%) & $151(87.8 \%)$ \\
\hline Single Access (n,\%) & $163(94.7 \%)$ \\
\hline Double Access (n,\%) & $9(5.3 \%)$ \\
\hline Stone-Free (n,\%) & $162(94.1 \%)$ \\
\hline
\end{tabular}

None of the patients with intercostal access had a hydrothorax or pneumothorax. Seven patients $(4.1 \%)$ had a fever up to $38^{\circ} \mathrm{C}$ postoperatively, who were treated successfully with appropriate antibiotics and antipyretic treatment. Headache due to SA and hemorrhage requiring blood transfusion were observed in $10(5.8 \%)$ and $5(2.9 \%)$ patients, respectively. Three patients $(1.7 \%)$ had a prolonged drainage ( $>24$ hours) from the nephrostomy tract after the nephrostomy tube was removed. These patients were evaluated with KUB x-ray, US or CT, and were replaced a double-J (DJ) stent as no residual stone was identified. Two patients $(1.1 \%)$ had a perirenal hematoma managed with conservative follow-up. No adjacent intra abdominal organ injury or urosepsis was observed in any of the patients; and no patient required a conversion to open surgery (Table 2).
Table 2 Complications according to the modified Clavien-Dindo classification

\begin{tabular}{|l|l|}
\hline Complication & $\mathbf{n}(\%)$ \\
\hline No Complication & $128(74.4 \%)$ \\
\hline Grade I & $7(4.1 \%)$ \\
\hline Hever & $10(5.8 \%)$ \\
\hline Grade 2 & $5(2.9 \%)$ \\
\hline Blood Transfusion & $3(1.7 \%)$ \\
\hline Haematuria (>48 h) & \\
\hline Grade 3a & $3(1.7 \%)$ \\
\hline Prolonged drainage(>24 h) & \\
\hline Grade 3b & $2(1.1 \%)$ \\
\hline Perirenal Hematoma & $4(2.3 \%)$ \\
\hline Need for Ureterorenoscopy & \\
\hline
\end{tabular}

\section{Discussion}

Urinary stone disease, with an existence almost as old as human history, is seen endemically in our country as well as in some of the countries in the world. ${ }^{11}$ Conservative, medical or surgical treatment modalities can be used in the management of urinary stone disease. PCNL has been the gold standard treatment option in large stones, and has lowered the rate of open surgery down to $2-5 \%$ due to its advantages, namely shorter hospitalization and convalescent periods, higher success rate, lower cost, and better cosmetic results. ${ }^{12,13}$

Residual stone fragments may cause pain, infection, and obstruction in the urinary tract postoperatively as well as a need for re-operation; thus, stone-free rate is crucial in PCNL. Although there is no consensus on which criteria should be taken into consideration for the evaluation of PCNL success, the term "clinically insignificant residual fragment (CIRF)" is commonly used nowadays. Stone fragments smaller than $4 \mathrm{~mm}$ and which do not cause infection, pain or obstruction are considered to have no effect on the operation success. ${ }^{14}$ Anatomical abnormalities, inappropriate surgical technique, stone composition, and technical difficulties may affect the number and size of the residual stone fragments..$^{15}$

PCNL success rates, directly affected by the surgeon's experience, anatomical structure of the kidney, and localization, size and composition of the stones, differ between $72-98 \%$ in large series. ${ }^{16,17}$ Segura et al. ${ }^{18}$ published their success rate as $98 \%$ in their early series of 1000 cases in 1989 . A stone-free rate ranging between $53.8 \%$ and $98 \%$ has been reported in series with different anesthesia methods, and it has been concluded that performing PCNL under spinal anesthesia does not have an effect on the operation outcomes. ${ }^{6-8}$ In parallel to these results in the literature, we observed a complete stone-free rate of $89 \%$ and a CIRF rate of $5 \%$ in our series. Sofikerim et al. ${ }^{19}$ have found the surgeon's experience to be the most important factor affecting the outcome of the surgery. Stone burden is another important factor that affects the PCNL success. Clayman et al. have found that the success rate was $89 \%$ for the stones larger than $2 \mathrm{~cm}^{2}$ and $97-100 \%$ for the ones smaller than $2 \mathrm{~cm}^{2} .{ }^{20}$ In another study, success rate was found to 
be $88-91 \%$ and $7 \%$ for the stones smaller than and bigger than $3 \mathrm{~cm}$, respectively. ${ }^{21}$

Renal anatomy, size and localization of the stone, and surgeon's experience are important factors while determining the right access point and angle, and tract direction. Although the PCS can be reached more easily and clearly with an intercostal access, we generally preferred subcostal access because of the higher incidence of the complications, such as hydrothorax, pneumothorax, with an intercostal access. None of these complications occurred in our patients who had an intercostal access. PCNL seems to be an extremely reliable minimally invasive technique in experienced hands for treatment of urolithiasis; however, it should be kept in mind that complications which may even be life threatening might occur. Hemorrhage requiring transfusion, fever, and extravasation are the most frequent complications, while sepsis, injury to colon, pleura and lungs are rare major complications. ${ }^{22,23}$ Labate et al. ${ }^{24}$ observed a complication rate of $2.5 \%$ in their series, and reported fever and hemorrhage to be the most common complications. Regarding the complications specific to spinal anesthesia in PCNL, Mehrabi et al. ${ }^{7}$ reported a rate of 3.8\% for headache in their series with 160 patients. Transfusion rate has been reported to range between 6.3 and $10.9 \%$ in PCNL performed under spinal anesthesia. ${ }^{6-8}$ In our series, parallel to the findings in the literature, headache was the most common complication with an incidence of $5.8 \%$, and fever and hemorrhage requiring transfusion were observed in $4.1 \%$ and $2.9 \%$ of the patients, respectively. Hemorrhage requiring embolization or conversion to open surgery, urosepsis or injury to adjacent organs was not observed.

It has been reported that additional treatments, such as SWL, ureterorenoscopy, second-look PCNL and DJ stenting, is required with a rate of $10 \%$ after PCNL, even in experienced hands. ${ }^{25}$ Only $1.7 \%$ of the patients required DJ stenting because of prolonged drainage and $2.3 \%$ of the patients required ureterorenoscopy, while SWL or second-look PCNL was not performed. There are some studies that have showed that previous renal surgery does not affect the outcome of PCNL. ${ }^{26,27}$ In our series, $18 \%$ of the patients have had a previous surgery due to renal stones, and this did not have any effect on stonefree rates.

Hospitalization durations differ from each other in the few studies with PCNL under SA. It has been shown that anesthesia method does not have any effect on length of hospital stay, ${ }^{5,6}$ whereas Singh et al. observed a shorter hospitalization in patients whom undergone regional anesthesia. ${ }^{8}$ We observed the hospitalization duration to be 42 hours in our series that is in parallel to these findings. Moreover, it has been also shown that anesthesia method does not have any effect on the duration of fluoroscopy use.$^{6-8}$ Less blood loss, less postoperative pain, and a faster postoperative healing have been reported in patients undergone PCNL under SA., ${ }^{8,28}$ Moreover, lower complication rates, and better peri- and postoperative respiratory and hemodynamic profiles were observed in SA. ${ }^{29}$ As a conclusion, we think that SA does not negatively affect the operation performance and success rate, and can be used reliably for PCNL. In addition to this, patient being in cooperation with the surgeon during the operation may have a positive effect. Successful results can be obtained with PCNL under SA when performed for selected patients with appropriate indications and in experienced hands.

\section{References}

1. Curhan GC. Epidemiology of stone disease. Urol Clin North Am. 2007;34(3):287-293.
2. Fernström I, Johannson B. Percutaneous pyelithotomy: A new extraction technique. Scand J UrolNephrol. 1976;10(3):257-259.

3. Preminger GM, Tiselius HG, Assimos DG, et al. 2007 guideline for the management of ureteral calculi. J Urol. 2007;178(6): 2418-2434.

4. Türk C, Knoll T, Petrik A, et al. Guidelines on urolithiasis. European Association of Urology. 2015.

5. Kuzgunbay B, Turunc T, Akin S, et al. Percutaneous nephrolithotomy under general versus combined spinal-epidural anesthesia. $J$ Endourol. 2009;23(11):1835-1838

6. Tangpaitoon T, Nisoog C, Lojanapiwat B. Efficacy and safety of percutaneous nephrolithotomy (PCNL): a prospective and randomized study comparing regional epidural anesthesia with general anesthesia. Int Braz J Urol. 2012;38(4):504-511.

7. Mehrabi S, Karimzadeh Shirazi K. Results and complications of spinal anesthesia in percutaneous nephrolithotomy. Urol J. 2010;7(1):22-25.

8. Singh V, Sinha RJ, Sankhwar SN, et al. A prospective randomized study comparing percutaneous nephrolithotomy under combined spinalepidural anesthesia with percutaneous nephrolithotomy under general anesthesia. UrolInt. 2011;87(3):293-298.

9. Cicek T, Gonulalan U, Dogan R, et al. Spinal anesthesia is an efficient and safe anesthetic method for percutaneous nephrolithotomy. Urology. 2014;83(1): 50-55.

10. Pu C, Wang J, Tang Y, et al. The efficacy and safety of percutaneous nephrolithotomy under general versus regional anesthesia: a systematic review and meta-analysis. Urolithiasis. 2015;43(5):455-466.

11. Muslumanoglu AY, Binbay M, Yuruk E, et al. Updated epidemiologic study of urolithiasis in Turkey. I: Changing characteristics of urolithiasis. Urol Res. 2011;39(4):309-314.

12. Antonelli JA, Pearle MS. Advances in percutaneous nephrolithotomy. Urol Clin North Am. 2013;40(1):99-113.

13. Matlaga BR, Assimos DG. Changing indications of open Stone surgery. Urology. 2002;59(4):490-494.

14. Chongruksut W, Lojanapiwat B, Tawichasri C, et al. Predictors for kidney stones recurrence following extracorporeal shock wave lithotripsy (ESWL) or percutaneous nephrolithotomy (PCNL). J Med Assoc Thai. 2012;95(3):342-348.

15. Delvecchio FC, Preminger GM. Management of residual stones. Urol Clin North Am. 2000;27(2):347-354.

16. Hasun R, Ryan PC, West AB, et al. Percutaneous coagulum nephrolitotirpsy: a new approach. Br J Urol. 1985;57(6):605-609.

17. Michaels EK, Fowler JE, Manino M. Bacteriuria following ESWL of infected stones. J Urol. 1988;140:254-256.

18. Segura JW. The role of percutaneus surgery in renal and ureteral stone removal. J Urol. 1989;141(3 Pt 2):780-781.

19. Sofikerim M, Sahin A, Akdogan B. Percutaneusnephrolitotomy: our outcomes in 500 cases. Urology Bulletin. 2004;13:25-29.

20. Clayman RV, Mcdougall EM, Nakada SY. Endourology of the upper urinary tract: percutaneous renal and ureteral procedures. Wals PC, Retik AB, et al. (Eds.), Campbell's urology. Philadelphia: WB Saunders, USA, 1998;pp.2789-2874.

21. Lingeman JE, Coury TA, Newman DM, et al. Comparison of results and morbidity of percutaneous nephrostolithotomy and extracorporeal shock wave lithotripsy. J Urol. 1987;138(3):485-490.

22. Michel MS, Trojan L, Rassweiler JJ. Complications in percutaneous nephrolithotomy. Eur Urol. 2007;51:899-906. 
23. de la Rosette JJ, Opondo D, Daels FP, et al. Categorisation of complications and validation of the Clavien score for percutaneous nephrolithotomy. Eur Urol. 2012;62(2):246-255.

24. Labate G, Modi P, Timoney A, et al. on behalf of the CROES PCNL Study Group. The percutaneous nephrolithotomy global study: classification of complications. J Endourol. 2011;25(8):1275-1280.

25. Segura JW. Percutaneous Nephrolithotomy: Technique, indications, and complications; 1993 AUA Guidelines. 1993;12:154.

26. Gonen M, Cicek T, Ozturk B. Effects of previous open surgery on the outcomes of percutaneous nephrolithotomy. Turk J Urol. 2009;35:34-37.
27. Sofikerim M, Demirci D, Gulmez I, et al. Does previous open nephrolithotomy affect the outcome of percutaneous nephrolithotomy? J Endourol. 2007;21(4):401-403.

28. Richman JM, Rowlingson AJ, Maine DN, et al. Does neuraxial anesthesia reduce intraoperative blood loss? A meta-analysis. $J$ Clin Anesth. 2006;18(6):427-435.

29. Movasseghi G, Hassani V, Mohaghegh MR, et al. Comparison between spinal and general anesthesia in percutaneous nephrolithotomy. Anesth Pain Med. 2013;4(1):e13871. 